\title{
ENERGY CONSIDERATION IN METAL MACHINING
}

\author{
Sandeep Desai ${ }^{1}$, Swamini Chopra Raju Pawade ${ }^{2}$
}

Dept. of Mech Engg, Dr. Babasaheb Ambedkar Technological University, Lonere, Raigad-402103, M.S., India

1sandeepdesai022@gmail.com, 22chopra.swamini@gmail.com, 3rspawade@dbatu.ac.in

\section{ABSTRACT}

We cannot say that present day machining processes are clean. Current trends in the manufacturing sector will not be acceptable in the future. This will an arise need for extensive research and development work necessary to meet the environmental concern. Although research on promising green energy technologies manage to supply partially for current machining systems; the high energy-efficient machining systems that demand less energy remain important and highly desirable. The energy-efficient machining system requires a comprehensive understanding as well as optimization of energy consumption. This paper focuses upon the energy requirement during actual metal machining. The first part explains about the basics of energy in machining and the flow of energy in a production line. In the later part, two energy models are described that shows dependence of energy consumption in machining process upon the operating parameters and set-up parameters. Effects of these different parameters on specific energy consumption are also summarized. Finally, a brief introduction to few energy optimization techniques is given.

Keywords: Machining, Specific energy consumption, Energy models, Energy optimization.

\section{INTRODUCTION}

A significant use of energy for industrial operations is responsible for noteworthy $\mathrm{CO}_{2}$ emissions and thus the climate change. The energy consumed by the manufacturing industries accounts for $30 \%$ of the total world energy and results in $36 \%$ of the global $\mathrm{CO}_{2}$ emissions. Over the last decades, the demand for goods has increased and so has the demand for natural resources and energy. In addition, recently rising costs for energy and natural resources heavily burden the manufacturing companies all over the world. Hence, from both environmental and economic perspectives, improved energy efficient manufacturing is urgently required $[1,2]$.

Machining is a process of gradual removal of excess material from the pre-formed blanks in the form of chips. During continuous machining; the uncut layer of the work material just ahead of the cutting tool edge is subjected to almost all sided compression as indicated in Fig.1.

The force exerted by the tool on the chip arises out of the normal force, $\mathrm{N}$ and frictional force, $\mathrm{F}$ as indicated in Fig.1. Due to such compression, shear stress of different magnitudes develops within that compressed region in different directions and rapidly increases in magnitude. Whenever and wherever the value of the shear stress reaches or exceeds the shear strength of that work material in the deformation region; yielding or slip takes place resulting in shear deformation in that region.

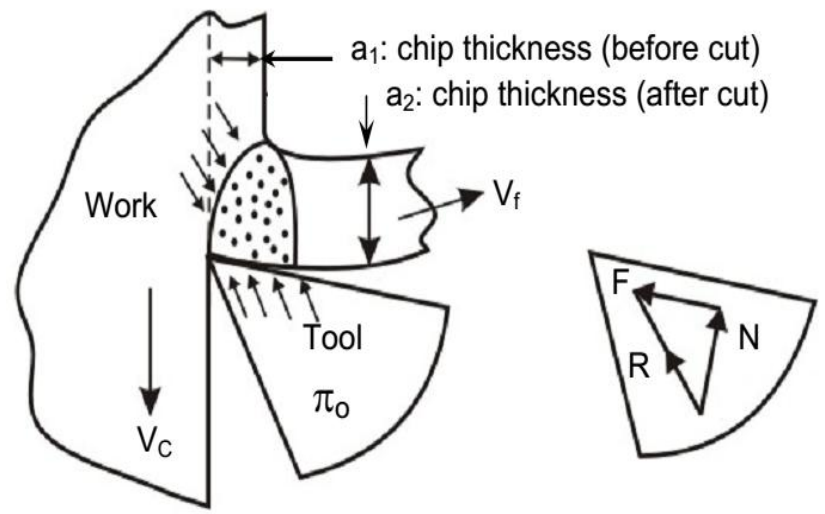

Fig.1 - Compression of work material layer ahead of the tool tip [3]

This cutting process constitutes some part of total energy input to the machine tool and process. Experiments on calculations of power consumption have shown that about 14 to $25 \%$ of the total energy is only used in actual machining. Remaining just goes into auxiliary devices, idle time and mechanical losses of the components [2,3]. Studies on energy-efficient machining systems concern the entire production chain with 
emphasis on energy behavior and its reduction on various levels. Table 1 shows a summary of literature related to the energy consumption in metal machining.

Table 1 - Summary of previous work on energy consumption in machining process

\begin{tabular}{|c|c|c|}
\hline $\begin{array}{l}\text { [Ref. } \\
\text { no.] }\end{array}$ & $\begin{array}{l}\text { First } \\
\text { Author }\end{array}$ & Energy Related Work \\
\hline [4] & Yuan & $\begin{array}{l}\text { - Suggests the measures to } \\
\text { reduce energy consumption }\end{array}$ \\
\hline [5] & Mori & $\begin{array}{l}\text { - Recommended strategies for } \\
\text { reduced energy based on } \\
\text { power consumption }\end{array}$ \\
\hline$[6]$ & Mativenga & $\begin{array}{l}\text { - Optimization of machining } \\
\text { conditions to minimize } \\
\text { energy utilization }\end{array}$ \\
\hline [7] & Salonitis & $\begin{array}{l}\text { - Proposed approaches to } \\
\text { improve energy efficiency }\end{array}$ \\
\hline [8] & Apostolos & $\begin{array}{l}\text { - Correlated energy efficiency } \\
\text { with machining parameters } \\
\text { and forces }\end{array}$ \\
\hline [9] & Rao & $\begin{array}{l}\text { - Proposed methods to reduce } \\
\text { energy consumption in a } \\
\text { factory }\end{array}$ \\
\hline [10] & Neugebauer & $\begin{array}{l}\text { - Envisaged role of cutting tool } \\
\text { material and geometry with } \\
\text { energy efficiency }\end{array}$ \\
\hline
\end{tabular}

\section{ENERGY ASPECTS IN METAL MACHINING}

In cutting a metal with a sharp tool, energy is spent mainly at the primary and secondary shear zone. As the material enters the cutting zone, shear deformation occurs first at the primary shear zone as shown in Fig. 2. Large strain and high-rate shear flow takes place there with moderate temperatures. The layer of material being removed is separated along the cutting edge. The energy consumed here is necessary for material removal and thus is considered useful energy. After passing the primary shear zone, the chip flows around the cutting edge and over the rake face of the cutting tool, forming the secondary shear zone that is characterized by severe friction and shear at the chip-tool interface with high temperatures. The energy consumed here is used to overcome friction and thus is considered non-productive [11].

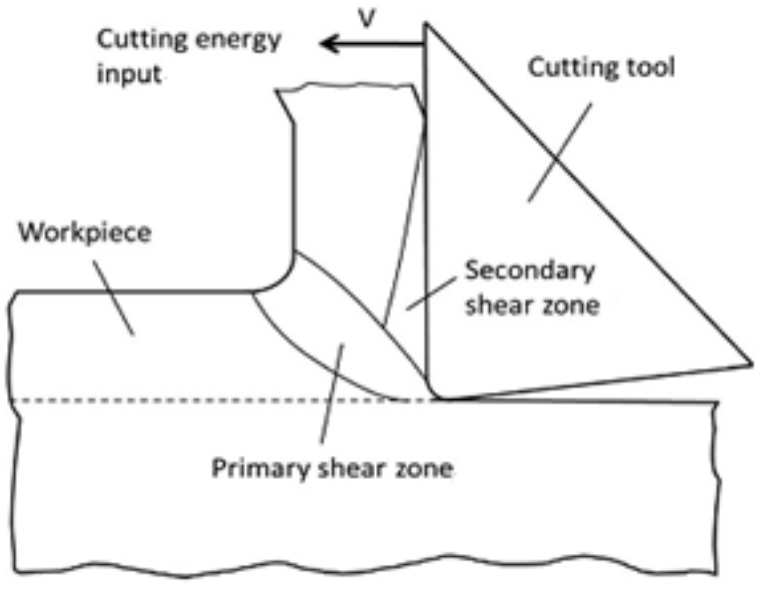

Fig. 2 - Energy components in metal machining [11]

Explained below are the basics of energy consumption calculations in metal machining [3]:

Cutting energy $E_{\mathrm{c}}$ can be calculated from the cutting power $P_{\mathrm{c}}$ as;

$$
E_{c}=P_{c} \times t_{c} \times 6 / 100
$$

The cutting power $P_{c}$ can be calculated based on the cutting force as;

$$
P_{c}=F_{c} \times V_{c / 60}
$$

The cutting speed can be expressed as:

$$
V_{c}=\frac{\pi \times D \times n}{1000}
$$

Therefore, it can be seen from the above equations that energy consumption studies can be relatedto cutting power, cutting force and cutting speed.

In some cases, total energy consumption can also be calculated as:

$$
E_{c}=E_{m} \times M R V
$$

where,

$E_{c}=$ cutting energy consumption $(\mathrm{kWh}), \boldsymbol{P}_{c}=$ cutting power $(\mathrm{W}), \boldsymbol{t}_{c}=$ cutting time (minutes), $\boldsymbol{F}_{\mathrm{c}}=$ cutting force $(\mathrm{N}), \boldsymbol{V}_{\mathrm{c}}=$ cutting speed $(\mathrm{m} / \mathrm{min}), \mathbf{D}=$ dia. of the workpiece in turning or dia. of cutting tool in milling and drilling $(\mathrm{mm})$, $\mathrm{n}=$ spindle speed (RPM), $\boldsymbol{E}_{\mathrm{m}}=$ energy consumption per unit material volume $\left(\mathrm{kWh} / \mathrm{mm}^{3}\right), \mathbf{M R V}=$ material removal volume $\left(\mathrm{mm}^{3}\right)$

Also, the total energy required by a machine tool for performing a specific process can be estimated using the equation as given below [7]: 


$$
E_{\text {total }}=E_{\text {process }}+E_{\text {auxiliary }}
$$

where, $\boldsymbol{E}_{\text {process }}$ is the energy required for the physical process to occur and $E_{\text {auxiliary }}$ is the additional energy consumed from the machine tool by the auxiliary devices. The process energy can be estimated from the specific cutting energy and it depends on the mechanics of the process, therefore, it depends on the process parameters [7]. The auxiliary energy can be further analyzed to the energy that is a function of the machine load and the energy consumed regardless whether the machine cuts or is idle (background energy) as can be seen in the following equation:

$$
E_{\text {auxiliary }}=E_{\text {background }}+E_{\text {load }}
$$

The background energy depends on the specific machine tool used and can be determined experimentally through an energy audit. The load energy depends on the workpiece characteristics (weight, material, size and properties), the process parameters selected and the cutting tool used [7].
A common characteristic of almost all the manufacturing processes is that even when the machine is idle; it is consuming more than $50 \%$ of its maximum power [7]. It can thus be concluded from these equations that there is lot of scope in energy reduction through proper planning and use of auxiliary devices. One such solution can be sharing ofone or more auxiliary devices that are common between two or more machine tools or production lines.

\section{ENERGY FLOW}

The study of energy flow pattern is the first crucial step to understand what the problem might be in case of energy consumption. Fig. 3 gives a representation of energy flow in a typical manufacturing industry According to Fig. 3; the top level i.e. "Enterprise level", receives the total energy input. They distribute the energy among different departments such as design, production, and management. Some part of total energy goes into a common sharing of lighting and heating-ventilation-air conditioning (HVAC) system, which may account for nearly $40-65 \%$ of total energy [13]. At enterprise level these components can be studied for energy savings by proper energy monitoring and management.

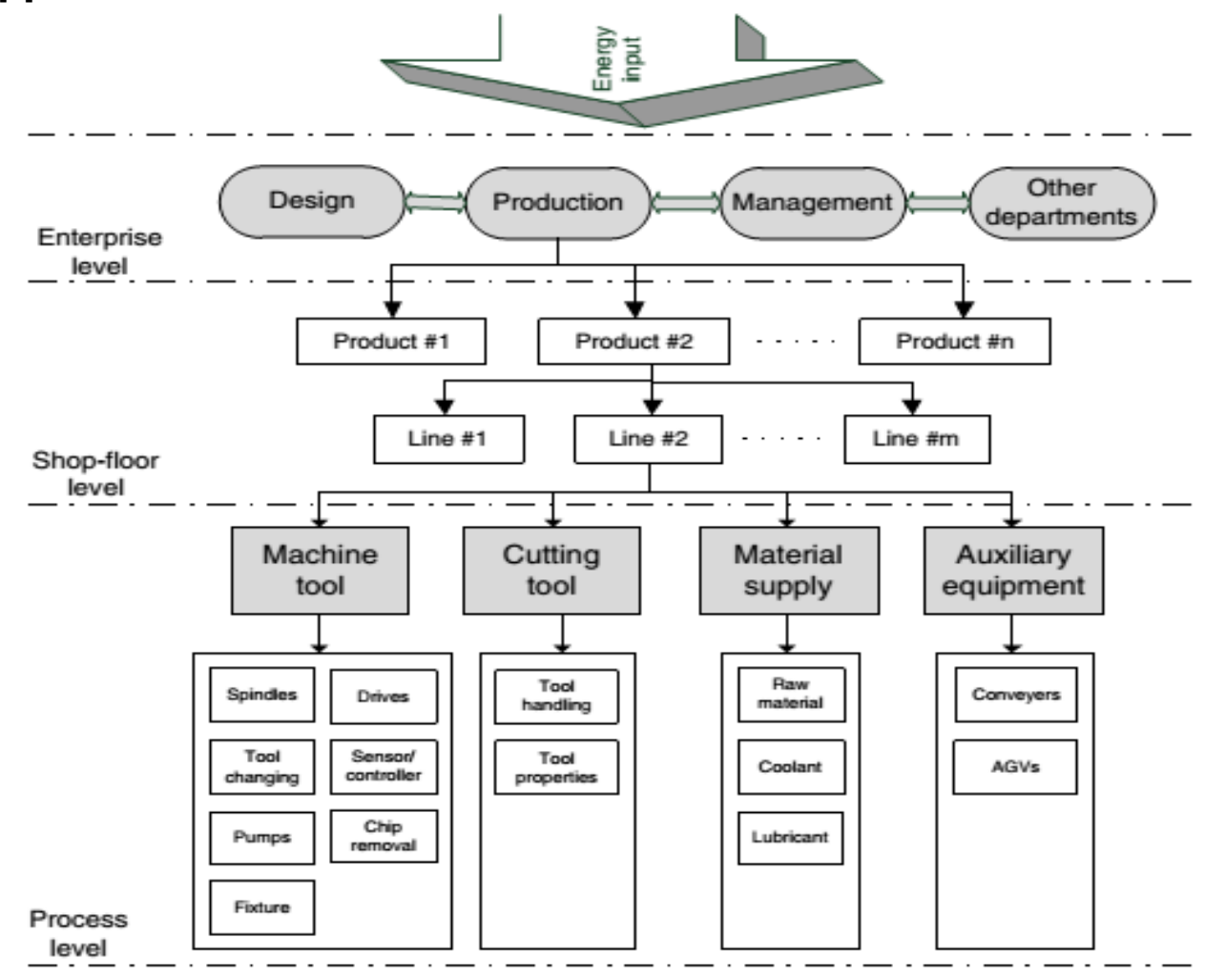

Fig. 3 - Overview of energy flow in a three-level structure [12] 
The production department can be considered as a major area of energy usage. For further scrutiny, it is then analyzed at "Shop floor level". The shop floor typically fabricates several products using one or more production lines. Each line consists of different machine tools and supporting devices that run along with each other for carrying out the production. This constitutes the bottom most level called "Process level". The challenge of reducing the energy consumption at shop floor level is optimum process scheduling between multiple products and production lines. Tactics to achieve energy savings at process level can be parameter optimization, use of energy efficient components and real time condition monitoring [3].

Gutowski et. al. [2] surveyed the "lean and green" manufacturing system of Toyota, Japan where the energy consumption of the production equipment was measured at different rates of production. One such result is shown in Fig. 4. It can be seen here that all most $85.2 \%$ of the total input energy is used by auxiliary devices. This leaves behind only $14.8 \%$ for actual machining operation.

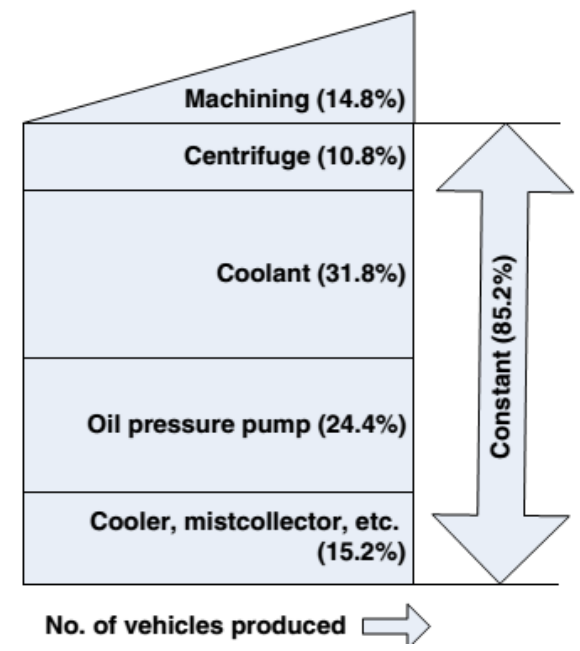

Fig. 4 - Breakdown of energy used for machining [2]

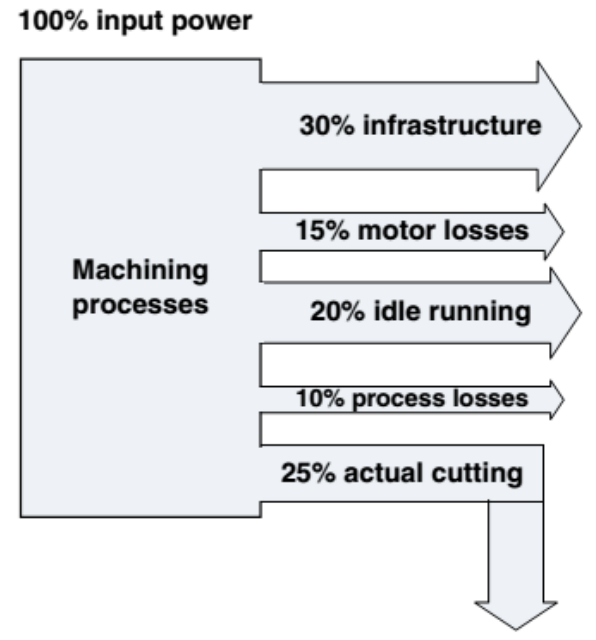

Fig. 5 - The distribution of the power consumed for a machine tool [3]

On similar lines; Peng and $\mathrm{Xu}$ [3] states that about $45 \%$ of total energy is consumed in idle time and system losses, while $30 \%$ goes into infrastructure such as lighting and HVAC. They conclude that only $25 \%$ of energy remains for actual cutting, as shown in Fig. 5. They conclude that developing and incorporating theoretical, empirical and/or discrete event-based models to establish a relationship between machining parameters and energy consumption in actual cutting can prove useful to optimize the energy consumption behavior of a machine tool system.

\section{ENERGY CONSUMPTION MODELS}

Energy consumption models for machining can prove a key to efficient manufacturing. Predicting the consumption rate beforehand can help one to crosscheck and keep under control the above mentioned parameters that influence the energy consumption. Munoz and Sheng [14] developed a model for both orthogonal and oblique cutting for examining the effect of input parameters and various tool geometry parameters upon the machining forces, process energy, material removal rate and environmental concerns. Equations 7 and 8 give cutting energy in orthogonal and oblique machining conditions respectively.

$$
\text { Energy }=\left(\frac{\cos (\beta-\gamma)}{\cos (\beta+\varphi-\gamma)}\right)\left(\frac{\tau_{5} \operatorname{MRV}}{\sin \varphi}\right)
$$

$$
\text { Energy }=\left(\frac{\cos (\beta-\gamma) \cos \eta_{5} \cos \hat{\lambda}+\cos (\varphi+\beta-\gamma) \sin \eta_{5} \sin \hat{\lambda}}{\cos (\varphi+\beta-\gamma)}\right) \frac{\tau_{5} \mathrm{MRV}}{\sin \varphi \cos \hat{\lambda}}
$$


where,

$\boldsymbol{\beta}=$ normal friction angle (radians), $\boldsymbol{\gamma}=$ normal rake angle (radians), $\boldsymbol{\varphi}=$ shear plane angle (radians), MRV = material removal volume, $\boldsymbol{\Lambda}=$ oblique angle (radians), $\mathbf{T}_{\mathbf{s}}=$ workpiece flow stress $(\mathrm{Pa}), \eta_{\mathrm{s}}=$ shear flow angle (radians)

From these equations it can be concluded that the cutting energy is independent of operating parameters. Instead, it is dependent on tool geometry, material selection and MRR.
Aggrawal et. al. [15] verified three different cutting environments to check which caused minimum power consumption in machining. They also took into account the tool radius as a representation of influence of tool geometry parameters on cutting power. Equation 9, 10 and 11are the empirical models proposed by the authors giving cutting power consumption for dry, wet and cryogenic cutting environment respectively.

$$
\begin{aligned}
P_{\text {cutting }}= & 1075.18-10.99 V_{c}-2444.44 V_{f}+1918.52 a_{p}+72.22 R \\
& +37.5 V_{c} V_{f}+4.58 V_{c} a_{p}+0.03 V_{c}^{2}-2222.22 a_{p}^{2} \pm 1133.33 \\
P_{\text {cutting }}= & 1832.28-2.67 V_{c}-1805.55 V_{f}+2191.36 a_{p}+23.44 V_{c} V_{f} \\
& +11.04 V_{c} a_{p}+1580.25 a_{p}^{2} \pm 600 \\
P_{\text {cutting }}= & 320.92-3.33 V_{c}-7888.88 V_{f}+51.85 a_{p}+161.11 R \\
& -6.25 V_{c} V_{f}+8.33 V_{c} a_{p}+541.66 .66 V_{f}^{2} \pm 533.33
\end{aligned}
$$

where,

$V_{c}=$ cutting speed, $V_{f}=$ feed rate, $a_{p}=$ depth of cut, $R=$ tool radius They concluded from these that the cryogenic cooling environment is the most efficient in minimizing cutting power consumption. Cutting speed and depth of cut have secondary impact, while feed rate and tool radius were found to have insignificant contribution. However, in addition the energy required to create the cryogenic environment should also be considered as a part of energy usage in this system.

\section{EFFECT OF PARAMETERS ON SPECIFIC ENERGY CONSUMPTION}

As concluded in previous section; the operating parameters have very little effect on energy consumption as compared to tool geometry. The effect of these parameters on the specific energy consumption in metal machining is summarized in Table 2.

Table 2 - Summary of the effects of various parameters on specific energy consumption

\begin{tabular}{|c|l|}
\hline Parameters & Effect on specific energy consumption \\
\hline $\begin{array}{c}\text { Cutting } \\
\text { speed }\end{array}$ & $\begin{array}{l}\text { - As cutting speed increases, the energy } \\
\text { consumption tends to reduce due to } \\
\text { reduction in cutting force }\end{array}$ \\
\hline Feed rate & $\begin{array}{l}\text { - An increase in feed rate will result in a } \\
\text { reduction in the specific energy } \\
\text { consumption which can be attributed to a } \\
\text { shorter process time }\end{array}$ \\
\hline Rake angle & $\begin{array}{l}\text { - Cutting energy decreases almost linearly as } \\
\text { rake angle moves from negative regime to } \\
\text { positive }\end{array}$ \\
\hline Nose radius & $\begin{array}{l}\text { - Cutting energy increases with nose radius } \\
\text { almost linearly due to an increase in the } \\
\text { main cutting force }\end{array}$ \\
\hline
\end{tabular}

\section{TECHNIQUES FOR ENERGY OPTIMIZATION}

Energy calculation data can be used in a number of different applications. Other than energy modeling; energy efficient systems can also help to achieve the goal of energy usage optimization. Three such techniques have been summarized in this section. 


\begin{tabular}{|c|c|c|}
\hline & Energy Optimization Techniques & \\
\hline $\begin{array}{l}\text { Re-designing Machine Tool } \\
\text { Structure }\end{array}$ & $\begin{array}{l}\text { Tool Condition Monitoring } \\
\text { (TCM) }\end{array}$ & Clean and Green Machining \\
\hline $\begin{array}{l}\text { Energy-efficient solutions } \\
\text { such as hydraulics and } \\
\text { pneumatics } \\
\text { Light-weight design can also } \\
\text { be used for energy saving }\end{array}$ & $\begin{array}{l}\text { - Provides real time energy } \\
\text { statusbased on tool condition } \\
\text { - Models integrating the tool } \\
\text { condition with drive power } \\
\text { can be developed }\end{array}$ & $\begin{array}{l}\text { - Focuses on the use of cutting } \\
\text { fluids, study of tool materials } \\
\text { and wet chips disposal } \\
\text { - Dry machining and } \\
\text { MQLproves to be potential } \\
\text { solutions }\end{array}$ \\
\hline
\end{tabular}

\section{CONCLUDING REMARKS}

From the above review, it can be concluded that:

- The actual cutting energy can be quite small when compared to the total energy required during the process.

- The energy used to power machine tools typically comes from the electricity. Thus, the electricity requirements for machining of metals must be properly controlled to minimize its environmental impact.

- With regards to cutting fluid use, one needs to incorporate an optimum solution which will minimize energy consumption without affecting the productivity and quality requirement.

- It can be concluded here that there is muchscope for research on energy management system.

\section{REFERENCES}

[1] Yansong Guo, Jef Loenders, Joost Duflou and Bert Lauwers, "Optimization of energy consumption and surface quality in finish turning", Procedia CIRP Vol. 1, (2012), pp. 551-556.

[2] T. Gutowski, C. Murphy, D. Allen, D. Bauer, B. Bras, T. Piwonka, P. Sheng, J. Sutherland, D. Thurston and E. Wolff, "Environmentally benign manufacturing: Observations from Japan, Europe and the United States", Journal of Cleaner Production, (2005), pp. 1-17.

[3] Tao Peng and Xun Xu, "Energy-efficient machining systems: a critical review", International Journal of Advanced Manufactuting Technology, (2014), pp. 13891406.

[4] C. Yuan, Q. Zhai and D. Dornfeld, "A three dimensional system approach for environmentally sustainable manufacturing", CIRP Annals Manufacturing Technolgy, (2012), pp. 39-42.

[5] M. Mori, M. Fujishima, Y. Inamasu and Y. Oda, "A study on energyefficiency improvement for machine tools", CIRPAnnals Manufacturing Technology, (2011), pp. 145148.

[6] P. T. Mativenga and M. F. Rajemi, "Calculation of optimum cutting parameters based on minimum energy footprint", CIRP Annals Manufacturing Technology, (2011), pp. 149-152.

[7] K. Salonitis and P. Ball, "Energy efficient manufacturing from machine tools to manufacturing systems", Procedia CIRP Vol. 7, pp. 634-639.

[8] F. Apostolos, P. Alexios, P. Georgios, S. Panagiotis and C. George, "Energy efficiency of manufacturing processes: a critical review", Procedia CIRP Vol. 7, (2013), pp. 628-633.

[9] B. C. Rao, "Methodology for adapting metal cutting to a green economy", Journal of Manufacturing Engineering, (2010), pp. 1193-1205.

[10] R. Neugebauer, A. Schubert, B. Reichmann and M/ Dix, "Influence exerted by tool properties on the energy efficiency during drilling and turning operations", CIRP Journal of Manufacturing Science and Technology, (2011), pp. 161-169.

[11] J. Ma, X. Ge, S. I. Chang and S. Lei, "Assessment of cutting energy consumption and energy efficiency in machining of 4140 steel", International Journal of Advanced Manufacturing Technology, (2014), pp. 17011708.

[12] Tao Peng and Xu Xun, "A framework of an energyinformed machining system", Proceedings of the 7th International Conference on Digital Enterprise Technology, Athens, Greece, (2011), pp. 160-169.

[13] N. Diaz, S. Choi, M. Helu, Y. Chen, S. Jayanathan, Y. Yasui, D. Kong, S. Pavanaskar and D. Dornfeld, "Machine Tool Design and Operation Strategies for Green 
Manufacturing", Proceedings of $4^{\text {th }}$ CIRP International Conference on High Performance Cutting, (2010).

[14] A. Munoz and P. Sheng, "An analytical approach for determining the environmental impact of machining processes", Journal of Materials Processing Technology, (1995), pp. 736-758.
[15] Aggarwal, H. Singh, P. Kumar, and M. Singh, "Optimizing power consumption for CNC turned parts using response surface methodology and Taguchi's technique - a comparative analysis", Journal of Material Process Technology, (2008), pp.373-384. 